\title{
Resident and staff perceptions of the content of their relationship in supported housing facilities for people with psychiatric disabilities
}

This article was published in the following Dove Press journal: Journal of Multidisciplinary Healthcare

\author{
David Brunt \\ Mikael Rask \\ Department of Health and Caring \\ Sciences, Linnaeus University, Växjö, \\ Sweden
}

Background: The work of staff in supported housing facilities for people with psychiatric disabilities has most often been studied from the perspective of one of the two groups but not from both. The staff in these facilities generally come from differing professions, reflecting either the beliefs of the medical or social models of psychiatric care.

Aim: The aim of the present study was thus to investigate the perceptions of residents and staff of the frequency and the importance of verbal and social interactions in supported housing facilities for people with psychiatric disabilities and to compare these perceptions. A further aim was to investigate whether differences in education background and other sociodemographic factors are reflected in the staff perceptions of these interactions.

Methods: One hundred and eleven residents living in supported housing facilities in Sweden and 223 staff completed the Verbal and Social Interaction Supported Housing questionnaire.

Results: The results revealed significant differences between the perceptions of the residents and staff on all six categories of interactions, where the staff rated the frequency and importance higher than the residents, but also some similarities in terms of the relative order of the frequency of the categories of interactions. Both the residents and staff perceived that "To build a relationship with a supportive quality" as the most frequently occurring and most important category. The mean levels of importance for all the categories were higher than for the frequency according to both groups. No differences were found between the staff with a medical or social educational background. Similarly, no differences were found in staff perceptions between those with short experience and those with long experience.

Conclusion: This study is the first survey of its kind and the results indicate the need for reducing the gap between the staff intentions and the residents' preferences, which could form the basis for in-house training activities.

Keywords: supported housing, psychiatric disability, residents, staff, interactions, relationships

\section{Introduction}

The nurse-patient relationship has been seen to be of great importance in psychiatric care. The verbal interactions between nursing staff and patients and the support given by the nursing staff that take place within this relationship have been described by researchers from both nursing and other fields as the cornerstones of this care. ${ }^{1-4}$ The integral nature of the work carried out by nurses and other staff is similar in many ways in the various types of psychiatric care settings., ${ }^{2,-8}$ Differences do, however, exist depending on the specific nature of the setting (forensic, inpatient or supported accommodation) and the location of care of people with long-term mental illness.
Correspondence: David Brunt School of Health and Caring Sciences, Linnaeus University, 35 I 95 Växjö,

Sweden

Tel +46 470708329

Fax +46 47036310

Email david.brunt@Inu.se 
In a literature review of staff-patient interactions in forensic psychiatric care, Gildberg et $\mathrm{al}^{9}$ found two overriding themes; a parentalistic and behavior-changing care and a relational and personal quality-dependent care. These themes appear to represent the two major aspects in play in forensic psychiatry: security and protecting society on the one hand and maintaining a therapeutic environment on the other hand. In an acute psychiatric context, Pitkänen et $\mathrm{al}^{10,11}$ have focused on the perceptions of both nurses and patients in two studies concerning interventions that can support quality of life in the patients. Interventions are often referred to in the same way as interactions in a nurse-patient context, however, the former can be construed as a one-way action whereas an interaction can be seen to better conform the mutuality and duality of a nurse-patient relationship. ${ }^{3}$ Hem and Pettersen ${ }^{12}$ have also emphasized the notion of reciprocity in asymmetric professional relationships in a psychiatric nursing context.

The geographical setting for mental health services, in particular for those with psychiatric disabilities, has changed from hospital-based units to a greater use of community-based supported accommodation that include both congregate and independent living solutions. ${ }^{13}$ From the staff perspective, Pejlert et $\mathrm{al}^{8}$ found that their work in supported housing, could be described as "sharing the activities of everyday life is a natural way of being together," "providing a warm, open and supportive caring atmosphere" and "sharing the client's everyday world with compassion and love, glimpsing possibilities." Kristiansen et al, ${ }^{14}$ on the other hand, found that staff experienced their role as care providers in supported housing included being similar to that of a parent and feeling an overwhelming frustration. Furthermore, the interactions of housing staff have been shown to encompass a number of aspects in which the residents need help and support in order to cope with life in the community. Examples of these aspects are: developing an ability to behave in a manner that is not deemed disturbing or irritating by others, ${ }^{15}$ and developing an ability for self-care and personal hygiene etc. ${ }^{16}$ Furthermore, Pejlert et al ${ }^{7}$ have discussed that talking to the residents and helping them to understand their "inner world" could be helpful in their struggle to better understand experiences and to gain more control over symptoms. In a study of mental health service recipients' experiences of the therapeutic relationship, Shattell et $\mathrm{al}^{17}$ found that these were expressed in three figural themes; "relate to me," "know me as a person" and "get to the solution."

Research on the relationships between people with psychiatric disabilities and professionals has concluded that the relationship is crucial in the process of recovery and for mediating support. ${ }^{18}$ Two studies, from the residents' perspective, have been found that focus specifically on the nurse/ staff-resident relationship in the supported housing context. Andersson ${ }^{19}$ maintained that supportive relationships involve a social climate with three components: an interest in the individual, care and concern for the individual and respect for the integrity of the individual. In a Norwegian study of residents' relationships, Rønning and Bjørkly ${ }^{20}$ found that the staff were described as what could be interpreted as idealizing self-objects who helped the residents cope with challenging situations in the community.

The congregate living solutions in Sweden, which are the focus for this study, are now generally termed "supported housing." The residents often have a private room or apartment, share some common areas with other residents and receive in-house staff support. The change of setting can influence the relationship between the staff and a resident in that the supported housing now constitutes the resident's own home, thus differing greatly from the inpatient setting. Furthermore, this type of setting also entails an extended remit for the staff in comparison to that in an inpatient unit. Nursing staff in inpatient units have responsibility for the care given there, while a member of the housing staff in supported housing has a responsibility for both the care given but also many other aspects of a person's life that take place in their own home and its surroundings. This extended assignment can also have a major influence on their relationship and interactions.

Furthermore, there are other aspects of this relatively new setting of supported housing, which also differ from hospital inpatient care, and which can also impact on the resident-staff relationship. The housing services in Sweden are run by the municipal social services but the setting in the community and the care provided there for people with psychiatric disabilities inherently contain elements from both the medical and the social work fields. There is at present no specific qualification for work in supported housing in Sweden and the staffing generally ranges from nurses, nurse assistants and licensed mental nurses with some form of training in psychiatric care to social workers, behavioral scientists and social care staff, thus reflecting the beliefs of the medical and social models of mental health care. ${ }^{21}$ Moreover, the National Board of Health Welfare recommends a broad range of qualifications with both specialists and generalists to meet the wide-ranging needs of the residents. ${ }^{22}$ During the development of housing solutions in Sweden for those with psychiatric disabilities, which began in earnest in 1990s, the municipalities recruited staff from the psychiatric services as they needed staff with experience of caring for those with long-term mental illness while not having experience of the specific context of housing. ${ }^{22}$ 
Studies of housing for people with psychiatric disabilities both internationally and nationally have focused on a wide variety of aspects of the housing environment and of the life of the residents. The nature of the work of the staff in this context, their relationship with the residents and the interactions between the two groups have, as shown above, either been studied from the perspective of one of the two groups but not from both of them. Furthermore, while the multidisciplinary nature of Community Mental Health Teams has been studied and differences found between social workers and health service professionals ${ }^{23}$ nothing is yet known of the possible impact of the interdisciplinary educational background of housing staff and other characteristics on their perceptions of the resident-staff interactions.

The aim of the present study was thus to investigate the perceptions of residents and staff of the frequency and the importance of verbal and social interactions in supported housing facilities for people with psychiatric disabilities and to compare these perceptions. A further aim was to investigate whether differences in education background and other sociodemographic factors are reflected in differences in the staff perceptions of these interactions.

\section{Materials and methods}

\section{Participants and data collection}

People with psychiatric disabilities living in supported housing facilities in five urban and rural municipalities and seven privately-run facilities in Sweden and the staff working in these facilities were invited to participate in the study. A total of 111 residents consented to participate and completed the VSI-SH questionnaire (see below). The mean age of the residents in this study was 45.6 and their mean length of stay was 5.1 years (Table 1). The residents in the supported housing facilities in the present study are people suffering from severe and long-term mental illness, mainly with psychosis or mood disorder diagnoses and are thus in all basic aspects similar to the general population of congregate supported housing facilities in Sweden. A total of 223 staff also completed the questionnaire.

The residents and staff each completed a resident or staff version of the VSI-SH questionnaire, respectively. The content of each item was the same in the two versions but the wording varied depending on whether the questionnaire was specifically formulated for one group or the other. The items presented in the results and the tables are from the residents' version. The terms residents and staff will be used in the rest of the paper to denote those living in supported housing facilities receiving care and those providing this care and support in these facilities. The term "staff" has been chosen to better suit the interdisciplinary nature of those working in supported housing facilities.

\section{Questionnaire}

The original Verbal and Social Interactions questionnaire (VSI) was developed to survey patients' and nurses' views on the frequency and importance of nursing interactions in forensic psychiatric care. ${ }^{24}$ The conceptual model, categories and items have been further described by Rask and Brunt. ${ }^{3}$ For the purpose of the present study, the original instrument was first adapted to suit the specific context of supported housing facilities culminating in 47 items and then reduced to a shorter version with 30 items and six categories VSISH (Table 3) in order to minimize factorial complexity and multiple loadings. ${ }^{25}$ The respondents were requested to

Table I Demographic characteristics of 1 II residents in supported housing

\begin{tabular}{|l|l|l|}
\hline Sex (n) & \multicolumn{2}{|l|}{ Residents } \\
\hline Female & 48 & \multicolumn{2}{|l|}{} \\
Male & 63 & Range \\
\hline & Mean & $20-82$ \\
\hline Age $(y)$ & 45.6 & $20-68$ \\
Female & 45.2 & $25-82$ \\
Male & 45.8 & $0-38$ \\
Present length of residence in & 5.1 & \\
small group home $(y)$ & & \\
\hline
\end{tabular}

Table 2 Demographic characteristics of 223 staff in supported housing

\begin{tabular}{|l|l|}
\hline & Staff \\
\hline Sex $(n)$ & \\
Female & 145 \\
Male & 68 \\
No information & 10 \\
Age (y, mean) (range) & $41.75(20-62)$ \\
Female & $42.04(20-62)$ \\
Male & $41.18(22-61)$ \\
Age subgroups ( $n)$ & \\
$20-35$ years & 68 \\
$\geq 50$ years & 58 \\
Education (n) & 164 \\
Licensed mental nurse/nurse assistant & \\
Graduate courses in social care/social work and & 40 \\
adjacent fields & \\
No information & 19 \\
Length of employment (mean) (range) & \\
Length of employment subgroups (n) & $5.0(0-24)$ \\
0-2 years & 62 \\
8-24 years & 44 \\
\hline
\end{tabular}

Note: ${ }^{E}$ Equivalent to junior and senior years in high school. 
assess both the frequency and importance of each item in a Likert-like scale with the response format ranging from not at all (1) to a very high degree (4). The face validity of this new version was tested among a group of experienced staff at a supported housing facility, the items were adjudged to be relevant, clear and readable.

\section{Data analysis}

For descriptive statistics, percentages were calculated for all items of interactions used by reducing the Likert scores of 1 (not at all) and 2 (to a small degree) to "low" category and scores of 3 (to a high degree) and 4 (to a very high degree) to "high" category. For comparison purposes, the staff educational background was reduced to two subgroups: medical and social, representing the two major educational spheres in the housing context. Two age subgroups were created for analyzing possible differences in staff perceptions due to age: younger staff (20-35 years) and older staff $(\geq 50$ years) and similarly two subgroups for length of employment were formed with short experience (0-2 years) and long experience (8-24 years). For the analysis of the staff sociodemographic variables and resident and staff perceptions of the VSI-SH categories, mean values and SDs were calculated and $t$-test was used. The computer-based program SPSS 24.0 (IBM Corporation, Armonk, NY, USA) was used for all analysis.

Table 3 Perceptions of residents and staff of the frequency and importance of verbal and social interactions, percentage of affirmative answers (High - very high degree: score 3 and 4) for each item

\begin{tabular}{|c|c|c|c|c|}
\hline & $\begin{array}{l}\text { Residents } \\
\text { frequency }\end{array}$ & $\begin{array}{l}\text { Staff } \\
\text { frequency }\end{array}$ & $\begin{array}{l}\text { Residents } \\
\text { importance }\end{array}$ & $\begin{array}{l}\text { Staff } \\
\text { importance }\end{array}$ \\
\hline \multicolumn{5}{|l|}{ To build a relationship with a supportive quality } \\
\hline The staff show you that you can feel safe with them & 70.6 & 98.2 & 81.4 & 100 \\
\hline The staff show you that they are honest & 68.5 & 96.8 & 79.0 & 98.6 \\
\hline The staff show you that they are true to their word & 70.6 & 98.6 & 85.4 & 99.1 \\
\hline The staff show you that they are honest and straightforward toward you & 73.4 & 94.6 & 77.7 & 97.7 \\
\hline The staff show you that you can believe in them & 68.5 & 97.3 & 80.4 & 97.7 \\
\hline The staff show you that you can trust them & 68.8 & 97.3 & 80.8 & 99.1 \\
\hline The staff encourage you to come and talk when you are having a difficult time & 60.7 & 93.7 & 79.2 & 96.8 \\
\hline The staff show you that they are there for you & 59.8 & 96.4 & 82.2 & 96.4 \\
\hline \multicolumn{5}{|l|}{ To support/encourage social skills } \\
\hline The staff encourage you to make new contacts with other people & 32.1 & 51.6 & 46.6 & 68.6 \\
\hline The staff encourage you to talk to other people & 37.6 & 57.3 & 48.0 & 69.2 \\
\hline The staff encourage you to be together with other people & 53.6 & 60.3 & 55.8 & 74.5 \\
\hline The staff encourage you to do things together with other people & 47.2 & 63.2 & 52.0 & 80.4 \\
\hline The staff support you to keep in contact with your relatives and friends & 33.6 & 49.8 & 47.6 & 67.3 \\
\hline \multicolumn{5}{|l|}{ To participate in joint social activities } \\
\hline The staff go on outings together with you & 49.5 & 49.3 & 68.6 & 72.4 \\
\hline The staff go out for a meal/cup of coffee together with you & 44.5 & 44.7 & 67.3 & 67.1 \\
\hline The staff do errands together with you (eg, going to the bank, etc.) & 43.6 & 72.5 & 61.5 & 83.0 \\
\hline The staff do things together with you & 46.8 & 62.8 & 57.3 & 81.7 \\
\hline The staff go shopping together with you & 46.8 & 63.4 & 51.4 & 72.5 \\
\hline \multicolumn{5}{|l|}{ To develop the resident's self-consciousness } \\
\hline The staff talk to you about your behavior when you are with other people & 32.4 & 53.4 & 32.4 & 70.3 \\
\hline The staff describe to you how you can behave when you are with other people & 23.1 & 49.5 & 31.7 & 68.8 \\
\hline The staff describe to you how you can express yourself & 35.8 & 47.5 & 43.0 & 71.4 \\
\hline The staff describe to you how they perceive your behavior & 37.4 & 58.9 & 41.6 & 76.3 \\
\hline The staff talk to you about how you perceive yourself & 36.1 & 45.9 & 43.1 & 67.0 \\
\hline \multicolumn{5}{|l|}{$\begin{array}{l}\text { To talk to the resident about his/her inner world, feelings and } \\
\text { perceptions }\end{array}$} \\
\hline The staff talk to you about your feelings & 35.8 & 66.8 & 60.2 & 80.0 \\
\hline The staff talk to you about how you think and feel about other people & 24.5 & 50.9 & 50.0 & 65.0 \\
\hline The staff describe to you how they see you as a person & 39.0 & 40.2 & 55.0 & 52.8 \\
\hline The staff talk to you about how you perceive your personal problems & 45.5 & 69.3 & 61.5 & 82.6 \\
\hline \multicolumn{5}{|l|}{ To develop the residents' practical skills } \\
\hline The staff encourage you to take care of your finance & 37.0 & 47.2 & 41.2 & 64.1 \\
\hline The staff talk to you about your eating habits & 30.9 & 51.1 & 41.3 & 71.0 \\
\hline The staff encourage/support you to keep your belongings in good order & 51.4 & 79.2 & 49.5 & 79.8 \\
\hline
\end{tabular}




\section{Ethical considerations}

This study conformed to the principles outlined in the Declaration of Helsinki and the Swedish National Board of Health and Welfare, and to the conditions stipulated by the University management that the informants were given the opportunity, both orally and in writing, to consent to participate in the study and that they could withdraw their consent and withdraw from the study at any time.

\section{Results}

Approximately, two-thirds of the staff were female and the mean length of employment was 5.0 years. A majority of the housing staff (73\%) were licensed mental nurses or nurse assistants (Table 2).

The presentation of the results for individual items in the following text and in Table 3 is made in percentages of the high category scores, ie, high or very high levels of the frequency and importance of each item. The presentation of the results for the instrument's six categories in the following text and Table 4 is made in terms of mean values due to aggregated data.

The residents perceived the categories of "To build a relationship with a supportive quality" and "To participate in joint social activities" as occurring the most often and "To develop the resident's self-consciousness" the least often (Table 4). At item level, the residents perceived all eight items of the relationship category as occurring most often with the item "The staff show you that they are honest and straightforward" as the most commonly occurring single item. The least frequently occurring item was "The staff describe to you how you can behave when you are with other people" from the "To develop the resident's self-consciousness" category (Table 3). Other items focusing on the residents contact with "other people" also occurred less frequently.

The staff also perceived the category of "To build a relationship with a supportive quality" as occurring the most often, while on the other hand there were only small visual differences between the mean high category scores for the other five categories (Table 4). At item level, the staff also perceived all eight items of the relationship category as occurring most often with the item "The staff show you that they are true to their word" as the most frequently occurring interaction. The least frequently occurring item was "The staff describe to you how they see you as a person" from the "To talk to the resident about his/her inner world, feelings and perceptions" category.

For the importance of the verbal and social interactions the residents perceived that the categories of "To build a relationship with a supportive quality" and "To participate in joint social activities" were the most important while the category "To develop the resident's self-consciousness" was the least important (Table 4). At item level, the residents perceived all eight items of the relationship category as being the most important with the item "The staff show you that they are true to their word" rated the most important single item. The least important items were "The staff describe to you how you can behave when you are with other people" and "The staff talk to you about your behavior when you are with other people" from the "To develop the resident's selfconsciousness" category (Table 3 ). The staff also perceived the category of "To build a relationship with a supportive quality" as being the most important, while there were small differences between the other five categories (Table 4). At item level, the staff also perceived all eight items of the relationship category as being most important with the item "The staff show you that you can feel safe with them" as the most important. The least important item according to the staff was "The staff describe to you how they see you as a person" from the "To talk to the resident about his/her inner world, feelings and perceptions" category (Table 3).

A comparison of the mean levels of the frequency and importance for all the categories (Table 4) showed

Table 4 Comparison of the perceptions of residents and staff of the frequency and importance of categories of nursing care interactions, mean (SD)

\begin{tabular}{|l|l|l|l|l|l|l|}
\hline & $\begin{array}{l}\text { Residents } \\
\text { frequency } \\
\text { mean (SD) }\end{array}$ & $\begin{array}{l}\text { Staff } \\
\text { frequency } \\
\text { mean (SD) }\end{array}$ & P-value & $\begin{array}{l}\text { Residents } \\
\text { importance } \\
\text { mean (SD) }\end{array}$ & $\begin{array}{l}\text { Staff } \\
\text { importance } \\
\text { mean (SD) }\end{array}$ & $\begin{array}{l}\text { P-value } \\
\text { To build a relationship with a supportive quality }\end{array}$ \\
$2.88(0.8)$ & $3.59(0.4)$ & 0.000 & $3.18(0.7)$ & $3.72(0.4)$ & 0.000 \\
\hline To support/encourage social skills & $2.24(0.8)$ & $2.68(0.6)$ & 0.000 & $2.48(0.8)$ & $2.99(0.6)$ & 0.000 \\
\hline To participate in joint social activities & $2.43(0.7)$ & $2.79(0.7)$ & 0.000 & $2.70(0.8)$ & $3.10(0.6)$ & 0.000 \\
\hline To develop the resident's self-consciousness & $1.98(0.8)$ & $2.60(0.6)$ & 0.000 & $2.21(0.8)$ & $2.95(0.6)$ & 0.000 \\
\hline $\begin{array}{l}\text { To talk to the resident about his/her inner world, } \\
\text { memories and experiences }\end{array}$ & $2.13(0.7)$ & $2.71(0.6)$ & 0.000 & $2.59(0.7)$ & $2.94(0.6)$ & 0.000 \\
\hline To develop the residents practical skills & $2.19(0.8)$ & $2.74(0.6)$ & 0.000 & $2.28(0.9)$ & $2.97(0.6)$ & 0.000 \\
\hline
\end{tabular}


considerably higher ratings for the importance than the frequency for both the residents and the staff. A similar result can be seen at item level where the importance of the items is rated higher than the frequency with the exception of one item in the residents' ratings and one for the staff (Table 3 ).

A comparison of the perceptions of the residents and staff revealed significant differences for all categories on both the frequency and the importance of the interactions (Table 4). The staff rated the levels of frequency higher than the residents on all categories (Table 4) and at item level the differences were $20 \%-36 \%$ for the majority of items while, however, there were three items where the difference was $1 \%$ or less: "The staff go on outings with you" and "The staff go out for a meal/cup of coffee together with you" from the "To participate in joint social activities" category and "The staff describe to you how they see you as a person" from the "To talk to the resident about his/her inner world, feelings and perceptions" category (Table 3 ). There were significant differences between the two groups on the perception of the importance of all the categories. A similar pattern emerged, as for the ratings of the frequency, in that the staff rated higher levels of the importance of the interactions for all of the categories (Table 4). At item level the differences were $15 \%-25 \%$ for a majority of the items while, however, for one item the residents rated the importance higher than the staff "The staff describe to you how they see you as a person" from the "To talk to the resident about his/her inner world, feelings and perceptions" category (Table 3). It is noticeable that the differences at item level for all items in the "To develop the resident's self-consciousness" category were highest, $27 \%-38 \%$.

The relative order of the frequency and importance of the categories differed somewhat between the two groups although the categories "To build a relationship with a supportive quality" and "To participate in joint social activities" were seen as the most frequent and important two categories of interactions by both groups.

In the analysis of the educational background and other sociodemographic factors in relation to staff perceptions of the interactions, no differences were found between the staff with a medical or social educational background. Similarly, no differences were found in staff perceptions between those with short experience and those with long experience. One difference was found, however, between the two age subgroups, where the younger staff (20-35 years) perceived that the category "To talk to the resident about his/her inner world, feelings and perceptions" was more important [3.07 (0.5)] than the older staff ( $\geq 50$ years), $[2.85(0.5)], P$-value (0.025).

\section{Discussion}

The results showed the frequency and importance of categories and items of verbal and social interactions as rated by the residents and staff in supported housing facilities for people with psychiatric disabilities. The results revealed significant differences between the perceptions of the residents and staff on all six categories of interactions but also some similarities in terms of the relative order of the frequency of the categories of interactions.

The category "To build a relationship with a supportive quality" was perceived as the most frequently occurring and most important of the categories by both residents and staff. The category contains items such as "The staff show you that you can feel safe with them," "The staff show you that they are true to their word" and "The staff show you that you can believe in them." The category thus contains those types of interactions that can be seen to be essential as a foundation for the creation and sustaining of relationships between residents and staff. These results correspond to the findings from several other studies where the importance of the relationship between patients/residents and staff, according to the patients, has been demonstrated..$^{8,17-19}$

At the other end of the scale, the "To develop the resident's self-consciousness" category is perceived as occurring the least frequently by both residents and staff and as being the least important by residents and the next least important by the staff. Together with the "To talk to the resident about his/ her inner world, feelings and perceptions" category that was also generally rated lower than other categories, the item content of these categories differs to some extent from the other categories in that the staff approach entails probing into more personal spheres and giving opinions about the residents' behavior. It is also notable that a further analysis of the least frequent interactions revealed that the four items (spread over three categories), with the lowest of the high category scores by the residents of the frequency of the interactions, all concern various aspects of the residents' contact with "other people". Although the staff perceive that they focus on these types of interactions to a greater extent than the residents have done, it may be that these more personal issues are ones that the staff may find greater difficulty in talking about the residents. Considering that difficulties in social contacts are common consequences of long-term mental illness it would appear that the staff should give more priority to helping the residents in their communication and behavior with other people.

The frequency of the verbal and social interactions was not at all on the same level as the importance attached to them. 
The level of importance of all the categories and a vast majority of the items were rated at higher levels than the frequency. This is not an uncommon feature of this type of study and a similar finding could be seen in the study using the original version of the VSI in a forensic psychiatric context. ${ }^{24}$ It is not unreasonable to assume that staff responses, to a request to assess the importance of their own interactions with residents in a supported housing facility, could be interpreted as an expression or indication of their intentions in their work. In a similar way the response from the residents, concerning the importance of these interactions, could be interpreted as a form of a "wants list," where higher scores indicate greater preferences. The visual differences between the levels of importance and frequency clearly indicate that the residents' own preferences and those of the staff differ greatly from their own perceptions of the frequency of the occurrence of these interactions. Furthermore, in the light of the now more generally accepted principles of person-centered care and their place in recovery-orientated practice, ${ }^{26}$ it would be justifiable to state that a housing facility of this nature, providing support to people with psychiatric disabilities, should have the residents' perceptions of the importance of the interactions as a measure or yardstick for the staff to aim to achieve in their everyday work. If the staff based their verbal and social interactions more on the residents' perceptions of what they think is important then the desired greater level of concordance between the two groups' perceptions of the frequency of the interactions could be achieved. This could entail a challenge to a not uncommonly held belief among nursing staff and other staff categories that they know best or at least better than those they are to help. It has been reported that despite the occurrence of shared decision-making and self-directed care in psychiatric services still remain at a low level and that greater empowerment for patients/residents is needed. ${ }^{27}$ Using the residents' perceptions of the importance of the verbal and social interactions, as presented in the VSI-SH, could be a significant help for focusing efforts to achieve a better person-centered care in supported housing environments.

The comparison of the perceptions of residents and staff reveals significant differences between the two for both the frequency and the importance of the interactions. Similar differences between patients and staff were found concerning the frequency of verbal and social interactions in a forensic psychiatric setting using the original VSI questionnaire. ${ }^{24}$ That study and the current one differ, however, in that the patients and nursing staff in the forensic setting differed only for one category in terms of the importance of the interactions. This finding is interesting and perhaps difficult to comprehend. One could expect greater differences between patients and nursing staff in a forensic psychiatric setting due to the involuntary nature of the care provided, while it is perhaps reasonable to expect differences in fewer aspects in a housing setting that does not have this element of coercion and which could be expected to impact less on the perceptions of the two groups.

On the other hand, differences between the perceptions of the two groups, as seen in the present study, are perhaps not so surprising. Differences between the two groups have, for example, been seen in the assessment of needs for people with long-term mental illness in community services. ${ }^{27,28}$ There can be a number of reasons for there being differences in perceptions between the groups. For example, contextual factors, ie, the two parties not sharing the same lifeworlds, and the two not having the same values, perhaps depending on their previous experiences. ${ }^{16}$ Furthermore, the staff have a duty to perform while for the residents, the housing facility is their home and at the same time the staff workplace. Whatever the reasons for the differences in perceptions between the two parties it is of great importance that the difference is reduced and a greater level of concordance is achieved. It is in some ways alarming that residents and staff perceive the frequency of the interactions so differently. One interpretation could be that the staff are unable to communicate fully their intentions with their various interactions so that the residents do not perceive them in the same way that the staff have intended. This can be overcome by the staff having a more open dialogue with the residents about the exact nature of what they do and what their intentions are and also taking into consideration possible cognitive impairments among the residents, which may contribute to them not comprehending the staff's actions in the way intended. Greater clarity in the dialogue and the actions together with an understanding of possible cognitive impairments could help to reduce the difference in perceptions of the occurrence of the interactions and lead to a better care.

It is noted in the "Results" section that the greatest differences between staff and residents on the importance of the interactions occurred in the category "To develop the resident's self-consciousness." The staff appear to recognize the importance of these items whereas it could be interpreted that the residents put less emphasis on these items, which are of a personal nature and potentially more sensitive and difficult. The staff appear to need to approach these issues carefully.

The result of the analysis of the two types of educational background, identified in the study, reflecting the medical and 
social models of mental health care revealed that there were no significant differences in the perception of the frequency and importance of the verbal and social interactions. It is possible that the congregate nature of the housing setting, which may entail a high level of teamwork, can contribute to blurring potential differences in the manifestation of the medical and social models in the everyday workings of supported housing. The staff, irrespective of which educational background they have, work together as a team in this setting. This thus differs from, for example a community mental health team setting, where there is a far greater level of individual encounters with the patients, who may only meet a few of the team. Furthermore, it could be that the medical and social models are well-integrated in the work at the supported housing facilities in terms of the broad remit that the staff have, which includes elements of a medical/caring nature, eg, symptoms, care and hygiene, and also of a social nature, eg, relationships, social activities and social skills. Another reason could be the focus of the questionnaire not being sufficiently sensitive to capture the nuances and differences that can exist but were not found in this study. A qualitative interview with staff with different educational backgrounds could perhaps penetrate further and reveal more about what the different qualifications provide in the work within supported housing for people with psychiatric disabilities.

A similar picture to the above was found in terms of sociodemographic factors, where only one difference was found for one category between younger and older staff. The lack of differences is somewhat surprising as younger staff with relatively shorter experience could perhaps be expected to display greater enthusiasm, drive etc., and give greater emphasis to certain of the interactions in comparison with their older colleagues.

\section{Conclusion}

The perceptions of the frequency and importance of the verbal and social interactions in congregate supported housing facilities by the residents and staff reveal interesting and notable differences concerning both the frequency and importance of the categories and items themselves but also the perceptions of the residents and staff. These differences can be seen to replicate to some extent those found in hospital-based services. The question can be raised as to whether these differences indicate potential institutional aspects in the relationships between residents and staff, which also impact in a housing context thus generating results of a similar nature, or whether they represent inherent differences between staff and care receivers that always exist in terms of the differing roles the two groups have. Differing educational backgrounds did not, however, appear to influence the perceptions of the staff. This study can be seen as a first survey of the field, which should be followed by more in-depth studies of the individual categories of verbal and social interactions in congregate supported housing facilities. At the same time, the results indicate the need for reducing the gap between the staff's intentions and the residents' preferences, which could form the basis for in-house training activities.

\section{Acknowledgment}

Financial support has been given by The National Board of Health and Welfare (Socialstyrelsen) in Sweden and by the School of Health and Caring Sciences, Linnaeus University, Sweden.

\section{Author contributions}

Both authors collected the data, contributed toward data analysis, drafting and revising the paper and agree to be accountable for all aspects of the work. Both authors read and approved the final manuscript.

\section{Disclosure}

The authors report no conflicts of interest in this work.

\section{References}

1. Barker PJ, Buchanan-Barker P. The Tidal Model: A Guide for Mental Health Professionals. New York: Brunner-Routledge; 2005.

2. Peplau H. Interpersonal Relations in Nursing. A Conceptual Frame of Reference for Psychodynamic Nursing. London: Macmillan Education; 1988.

3. Rask M, Brunt D. Verbal and social interactions in the nursepatient relationship in forensic psychiatric nursing care. Nurs Inq. 2007;14(2):169-176.

4. Topor A. Managing the Contradictions: Recovery from Severe Mental Disorders [dissertation]. Stockholm, Sweden: Stockholm University; 2001.

5. Morrison P, Burnard P. Caring and Communicating. The Interpersonal Relationship in Nursing. London: Macmillan Press; 1991.

6. Pejlert A, Asplund K, Norberg A. Stories about living in a hospital ward as narrated by schizophrenic patients. $J$ Psychiatr Ment Health Nurs. 1995;2(5):269-277.

7. Pejlert A, Asplund K, Norberg A. Towards recovery: living in a home-like setting after the move from a hospital ward. J Clin Nurs. 1999;8(6):663-673.

8. Pejlert A, Asplund K, Norberg A. From a psychiatric ward to a homelike setting: the meaning of caring as narrated by nurses. J Clin Nurs. 2000;9:689-700.

9. Gildberg FA, Elverdam B, Hounsgaard L. Forensic psychiatric nursing: a literature review and thematic analysis of staff-patient interaction. $J$ Psychiatr Ment Health Nurs. 2010;17(4):359-368.

10. Pitkänen A, Hätönen H, Kuosmanen L, Välimäki M. Patients' descriptions of nursing interventions supporting quality of life in acute psychiatric wards: a qualitative study. Int J Nurs Stud. 2008;45(11):1598-1606.

11. Pitkänen A, Hätönen H, Kollanen M, Kuosmanen L, Välimäki M. Nurses' perceptions of nursing interventions supporting quality of life in acute psychiatric wards. Perspect Psychiatr Care. 2011;47(4): $167-175$. 
12. Hem MH, Pettersen T. Mature care and nursing in psychiatry: notions regarding reciprocity in asymmetric professional relationships. Health Care Anal. 2011;19(1):65-76.

13. Brunt D. Supported Housing in the Community for Persons with Severe Mental Illness [dissertation]. Lund, Sweden: Lund University; 2002.

14. Kristiansen L, Hellzén O, Asplund K. Left alone - Swedish nurses' and mental health workers' experiences of being care providers in a social psychiatric dwelling context in the post-health-care-restructuring era. A focus-group interview study. Scand J Caring Sci. 2010;24(3): 427-435.

15. Högberg T, Magnusson A, Lützén K. Living by themselves? Psychiatric nurses' views on supported housing for persons with severe and persistent mental illness. J Psychiatr Ment Health Nurs. 2006;13(6):735-741.

16. Bengtsson-Tops A. Behov av vård och stöd [Needs for care and support]. In: Brunt D, Hansson L, editors. Att leva med psykiska funktionshinder- livssituation och effektiva vård-och stödinsatser [Living with psychiatric disabilities - life situation and effective care and support]. Lund: Studentlitteratur; 2005:139-156. Swedish.

17. Shattell MM, Starr SS, Thomas SP. "Take my hand, help me out": mental health service recipients' experience of the therapeutic relationship. Int J Ment Health Nurs. 2007;16(4):274-284.

18. Borg M, Kristiansen K. Recovery-oriented professionals: Helping relationships in mental health services. J Ment Health. 2004;13(5):493-505.

19. Andersson G. What makes supportive relationships supportive? The social climate in supported housing for people with psychiatric disabilities. Soc Work Ment Health. 2016;14(5):509-529.

20. Rønning SB, Bjørkly S. Residents' experiences of relationships with nurses in community-based supported housing - a qualitative study based on Giorgi's method of analysis and self psychology. J Multidiscip Healthc. 2017;10:65-74.
21. Andersson G. Vardagsliv och boendestöd - en studie om människor med psykiska funktionshinder [Everyday life and housing support - a study of people with psychiatric disabilities] [dissertation]. Stockholm, Sweden: Stockholm University; 2009. Swedish.

22. Swedish National Board of Health and Welfare. Det är mitt hem Vägledning om boende och boendestöd för personer med psykisk funktionsnedsättning [This is my home - guidelines for housing and housing support for people with psychiatric disabilities]. Stockholm, Sweden: Socialstyrelsen; 2010; Swedish.

23. Carpenter J, Schneider J, Brandon T, Wooff D. Working in multidisciplinary community mental health teams: the impact on social workers and health professionals of integrated mental health care. Br J Soc Work. 2003;33(8):1081-1103.

24. Rask M, Brunt D. Verbal and social interactions in Swedish forensic psychiatric nursing care as perceived by the patients and nurses. Int J Ment Health Nurs. 2006;15(2):100-110.

25. Brunt D, Rask M. Validation of the verbal and social interaction questionnaire: carers' focus in the carer-resident relationship in supported housing facilities for persons with psychiatric disabilities (VSI-SH). J Psychiatr Ment Health Nurs. 2013;20(3):279-285.

26. Smith GP, Williams TM. From providing a service to being of service: advances in person-centred care in mental health. Curr Opin Psychiatry. 2016;29(5):292-297.

27. Brunt D, Hansson L. Comparison of user assessed needs for care between psychiatric inpatients and supported community residents. Scand J Caring Sci. 2002;16(4):406-413.

28. Hansson L, Vinding HR, Mackeprang T, et al. Comparison of key worker and patient assessment of needs in schizophrenic patients living in the community: a Nordic multicentre study. Acta Psychiatr Scand. 2001;103(1):45-51.
Journal of Multidisciplinary Healthcare

\section{Publish your work in this journal}

The Journal of Multidisciplinary Healthcare is an international, peerreviewed open-access journal that aims to represent and publish research in healthcare areas delivered by practitioners of different disciplines. This includes studies and reviews conducted by multidisciplinary teams as well as research which evaluates the results or conduct of such teams or health

\section{Dovepress}

care processes in general. The journal covers a very wide range of areas and welcomes submissions from practitioners at all levels, from all over the world. The manuscript management system is completely online and includes a very quick and fair peer-review system. Visit http://www.dovepress.com/ testimonials.php to read real quotes from published authors. 